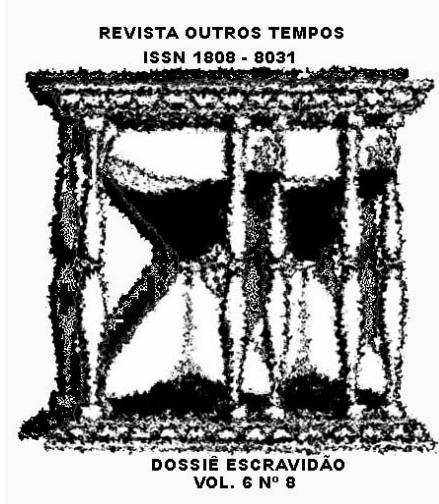

\title{
A CONTRIBUIÇÃO DA MEMÓRIA PARA O ESTUDO DE UM PROCESSO IMIGRATÓRIO ESPECÍFICO: o caso dos sírios e libaneses em Juiz de Fora - MG (1890- 1940)
}

\section{RESUMO}

Juliana Gomes Dornelas

Mestre em História pela Universidade Federal de Juiz de Fora

(UFJF)

gomesdornelas@yahoo.com.br

O presente artigo é parte de nosso estudo de mestrado sobre os imigrantes sírios e libaneses instalados em Juiz de Fora, Minas Gerais. Buscamos através da memória, estudar de maneira mais aprofundada os sírios e libaneses e seus descendentes em Juiz de Fora. Através da oralidade e da memória, ou seja, das entrevistas com os descendentes de sírios e libaneses, construímos um modelo de instalação destes grupos em Juiz de Fora apontando os motivos da partida da terra natal, como foi a chegada destes na cidade, em que trabalhavam, onde moravam, como era a relação com os locais, qual gastronomia predominava, dentre outros pontos. Foi através da memória que pudemos perceber a versão daqueles que realmente vivenciaram o processo imigratório e que através da sua fala puderam contribuir para esclarecer um pouco mais sobre este grupo imigrante em questão.

Palavras-chave: Sírios e Libaneses. Imigrantes. Juiz de Fora. Memória.

\begin{abstract}
This article is a part of our master degree study about the syrian immigrants and lebaneses settled down in Juiz de Fora, Minas Gerais. We intended, trough the memory, to study deeply the Syrian and lebaneses and their descendents in Juiz de Fora. Trough the orality and the memory, in the other words, interviewers with descendents from Syrians and lebaneses, we made a model about how these groups were settled down in Juiz de Fora, pointing the causes of the departure from their homeland, how the arrival in the city was, what they used to do, where they used to live, how the relation with the places was, what kind of food they used to eat, among other things. Trough the memory, we could see the version of those people that really lived the process of immigrantion and trough the interviewers, they could contribute to clear about this immigrant group that we are discussing about.
\end{abstract}

Keywords: Syrians and Lebaneses. Immigrants. Juiz de Fora. Memory. 
Juiz de Fora nasceu a partir de 1709, às margens do Caminho Novo, estrada que ligava o sudoeste da Zona da Mata ao Rio de Janeiro (OLIVEIRA, 1991, p. 45), e que facilitou o acesso ao interior para comerciantes vindos de fora, fazendo com que ao longo deste novo caminho formassem pequenas vilas e povoados, que acabaram contribuindo para a permanência dos tropeiros na região (MIRANDA, 1990, p. 85). A vila era denominada Santo Antônio do Paraibuna, e foi elevada à cidade em 1856, mantendo-se o mesmo nome. Em 1865 foi renomeada, passando a chamar-se Juiz de Fora (OLIVEIRA, 1966, p. 37; 63).

A partir de 1830 começou a haver a definição de um caráter urbano do espaço que antes estava dividido em sesmarias. Em Minas Gerais, a Zona da Mata destacou-se como principal região cafeicultora e Juiz de Fora tornou-se seu centro dinâmico por excelência, sendo local de escoamento da safra para o Rio de Janeiro, onde se comercializava o produto. Além disso, esta cidade possuía uma rede de serviços urbanos e comerciais de apoio a produção do café, e ao longo do tempo, no final do século XIX, apresentou-se enquanto importante centro industrial (OLIVEIRA, 1991, p. 12).

$\mathrm{Na}$ década de 1850, foi criada a Companhia União Indústria, responsável pela construção de uma rodovia macadamizada (que interligava a província de Minas Gerais à província do Rio de Janeiro), o que fez esta região crescer ao diminuir os problemas de comunicações, e ao encurtar a viagem entre a corte e Minas, o que facilitava o transporte do café (MONTEIRO, 1994, p. 14). Para a construção desta rodovia chegaram a Juiz de Fora os primeiros imigrantes alemães que foram acomodados na colônia Dom Pedro II, fundada em 1857. O mentor da vinda destes estrangeiros foi Mariano Procópio, proprietário da Companhia União Indústria (OLIVEIRA, 1991, p. 50; 56).

A expansão urbana juizforana acelerou-se a partir de 1860. Este processo de urbanização, influenciado pelo avanço da industrialização, atraía de tal forma pessoas de outras regiões e mesmo da Zona da Mata, que tornou-se possível um aumento populacional significativo, como mostram os dados do censo a seguir (MIRANDA, 1990, p. 99-100). Em 1855, o município contava com 27.722 habitantes; em 1890, trinta e cinco anos depois, a população deste $^{1}$ elevou-se a 55.185 pessoas (ESTEVES, 1915, s/p).

$\mathrm{Na}$ década de 1870 deu-se mais um passo para melhorar ainda mais as comunicações entre Juiz de Fora e outras cidades. Foram construídas neste período as estradas de ferro

\footnotetext{
${ }^{1}$ Estão inseridos no município os distritos de Juiz de Fora, Vargem Grande, Água Limpa, Paula Lima, Nossa Senhora do Rosário, Sant'Anna do Deserto, São Pedro de Alcântara, Porto das Flores, São José do Rio Preto, Sarandy, São Francisco de Paula, São Sebastião da Chácara e Mathias Barbosa. In: ESTEVES, Albino. Álbum do Município de Juiz de Fora. Bello Horizonte: Imprensa Official do Estado de Minas, 1915. Alocado no centro de Memória Murilo Mendes - Juiz de Fora.
} 
Leopoldina e Dom Pedro II, que tornaram mais rápido o transporte do café (OLIVEIRA, 1966, p. 51). Devido ao desenvolvimento desta cidade decidiu-se construir nesta a Hospedaria dos Imigrantes, que receberia os estrangeiros e os encaminharia para a região. O estabelecimento foi fundado em maio de 1889, com o nome de Hospedaria Horta Barbosa (MONTEIRO, 1994, p. 26).

A indústria e a agricultura em crescimento precisavam de mão-de-obra que aceitassem uma forma de trabalho no modelo capitalista industrial. Os homens livres pobres passavam por uma espécie de ensino agrícola e técnico que tinha como objetivo a adaptação destes às novas necessidades, ou melhor dizendo, à nova disciplina do trabalho. A imigração constituiu uma forma mais fácil de ter um trabalhador "já feito", já acostumado com as novas regras capitalistas. Entretanto, isto não significava que mesmo os considerados desejáveis se sujeitassem a qualquer forma de contrato. Muitos, quando não gostavam das condições em que se encontravam, fugiam para o Rio de Janeiro ou São Paulo. Estes almejavam autonomia profissional, pois viam o trabalho como lucro (CHRISTO, 1994, p. 103; 106).

Neste processo de busca pela independência financeira encaixam-se os imigrantes sírios e libaneses, que deixaram sua terra a fim de conseguirem um trabalho independente que os fornecesse meios de acumular pecúlio de forma rápida. Esse dinamismo da economia e da vida social verificado na passagem do século XIX para o XX em Juiz de Fora pode ter atraído este grupo para a cidade. Mas isto não quer dizer que eles só se dirigiam para lugares em processo de urbanização crescente, pois eles também foram encontrados em locais pouco desenvolvidos (onde poderiam estabelecer-se enquanto primeiros comerciantes). O objetivo deles era viver e trabalhar em um local onde pudessem obter uma vida melhor, e Juiz de Fora talvez os tenha atraído pelo fato de estar em desenvolvimento e por possuir uma área urbana que comportasse investidores e todos os tipos de comércio e atividades. Esta cidade era marcada pelo fato de atrair aqueles estrangeiros que não eram agricultores e que tinham uma experiência prévia (OLIVEIRA, 1991, p. 113). Este é o caso dos sírios e libaneses, que mesmo sendo agricultores em sua terra natal, também se dedicavam à venda dos produtos que lá plantavam, possuindo assim um conhecimento básico de comercialização.

\section{A memória ajudando a construir a história de um grupo: os sírios e os libaneses em Juiz de Fora}

Os sírios e libaneses cristãos começaram a chegar a Juiz de Fora a partir do final do século XIX. A partir de estudos já feitos sobre a memória local dos sírios e dos libaneses 
reconhece-se que Salim Nicolau teria sido o primeiro imigrante libanês que instalou-se na cidade, na década de 1890, juntamente com seu irmão Demétrio. Já os sírios estabeleceram-se neste local mais tardiamente, por volta de 1913, processo provavelmente iniciado por Neman Salomão (BASTOS, 1988, p. 8; 23). Os libaneses vieram em maior número para esta região, perfazendo um total de 300 famílias, enquanto os sírios somavam apenas 69 (PEQUENO, 2000, p. 30). Já em 1893 temos a recorrência deste grupo no censo da cidade.

TABELA 1 - Censo de 1893

\begin{tabular}{l|lll}
\hline Nacionalidade & Qtde & Nacionalidade & Qtde \\
\hline Italianos & 1197 & Russos & 05 \\
Portugueses & 501 & Argentinos & 04 \\
Alemães & 328 & Chineses & 02 \\
Espanhóis & 80 & Polacos & 02 \\
Franceses & 66 & Prussianos & 01 \\
Árabes & 27 & Irlandeses & 01 \\
Austríacos & 22 & Egípcios & 01 \\
Ingleses & 18 & Total de Estrangeiros & 2276 \\
N. Americanos & 15 & Total de Brasileiros & 7924 \\
\hline Suíssos & 06 & Total de Habitantes & 10.200 \\
\hline
\end{tabular}

Fonte: Recenseamento da População de Juiz de Fora residente no perímetro da cidade. Arquivo da Prefeitura Municipal de Juiz de Fora. Fundo Câmara Municipal, República Velha. Série 164. Caixa 120.

Observando a tabela acima, percebemos a princípio que estes imigrantes não eram chamados de sírios ou libaneses, e sim árabes. Além disso, observamos que o maior número de estrangeiros na cidade é de italianos, portugueses e alemães, somando 2026. Considerando que havia neste ano um total de 2276 pessoas de outras nacionalidades no perímetro urbano, conclui-se que os três primeiros representam $89 \%$ dos imigrantes que estavam inseridos nesta cidade, frente aos $11 \%$ dos outros 14 grupos. Os sírios e libaneses contavam neste momento com 27 integrantes e encontravam-se em sexto lugar.

Em 1900 temos uma elevação do número do grupo em questão no território juizforano. O jornal $O$ Pharol, periódico desta cidade, nos informa o resultado do recenseamento do distrito de Juiz de Fora, realizado em 31 de dezembro daquele ano. A cidade contava então com 18055 habitantes, sendo 14757 brasileiros e 3298 estrangeiros, dentro os quais temos: 2047 italianos, 642 portugueses, 387 alemães, 55 espanhóis, 38 árabes, 31 belgas, 26 
franceses, 21 norte-americanos, 19 africanos, 12 ingleses, 15 austríacos, 2 chineses, 1 húngaro, 1 russo e 1 dinamarquês (O PHAROL, 1901, p. 1). Neste ano os italianos novamente foram os mais numerosos, já os sírios e libaneses subiram uma posição, deixando o sexto para o quinto lugar, devido a queda do número de franceses, a chegada de 31 belgas, e o aumento de 11 árabes em sete anos.

Quanto aos sírios e libaneses, de onde vieram? Como vieram? Estas questões podem ser respondidas ao trabalharmos com uma série de entrevistas que realizamos com descendentes de sírios e libaneses nesta cidade. Alguns entrevistados vieram tardiamente se compararmos ao nosso recorte cronológico que vai até a década de 30 do século XX. No entanto, eles nos forneceram um rico relato dos seus parentes que chegaram antes e dos motivos da saída de sua terra natal.

Escolhemos trabalhar com a memória oral com o intuito de perceber a visão dos próprios imigrantes e seus descendentes sobre todo o processo de inserção em uma nova cultura, tentando ultrapassar os limites de outros tipos de fontes fortemente marcados por um olhar externo ao mundo dos que emigraram. As representações que uma pessoa faz, ou mesmo uma geração inteira tem de si e de sua época, devem ser consideradas fatos que refletem a realidade e não construções sem sentido. Consideramos então, que os relatos orais, as biografias, os relatos de vida, embora sendo baseados em um indivíduo, concentram as características de um grupo, mostrando o que é próprio a este (ALBERTI, 2004, p. 15). "Fazer história oral significa, portanto, produzir conhecimentos históricos, científicos, e não simplesmente fazer um relato ordenado da vida e da experiência dos outros" (LOZANO, 2002, p. 17).

Através da análise destes relatos percebemos que os que deixaram a localidade onde hoje se encontra o território libanês chegaram a Juiz de Fora, vindos de várias localidades como Ras Baalbek, Beit Edine, Jbail, Deir El Kamar, Al Hassun, dentre outras. ${ }^{2}$ Entre elas, apenas duas são próximas a área costeira. Ras Baalbek localiza-se mais para o interior do território libanês.

Já os sírios, vieram em sua maioria da cidade de Yabroud. Esta cidade localizava-se a 70 quilômetros da capital Damasco e vivia da agricultura de subsistência e da produção artesanal de mantas de pele de cabra, para montar tendas que abrigavam os animais (ALMEIDA, 2000, p. 194).

\footnotetext{
${ }^{2}$ Dados retirados das entrevistas que realizamos com os descendentes dos primeiros imigrantes em Juiz de Fora. Todas as entrevistas aqui citadas estão transcritas e disponíveis para consulta no Arquivo Histórico da Universidade Federal de Juiz de Fora, Juiz de Fora - MG.
} 
O relato de Dona Mounira Haddad, síria, nos ajuda a compreender como eram feitas estas tendas. Dona Mounira, síria, deixou a cidade de Yabroud acompanhando seu marido logo que se casaram. Vieram direto para Juiz de Fora, cidade onde seu esposo já estava morando antes de voltar em visita para a Síria. Dona Mounira Haddad Rahme, quando estava em sua terra natal, tinha como uma de suas atividades financeiras, junto de sua família, a feitura de tendas para animais. Segundo ela:

No tempo do inverno às vezes o frio e a neve vinha abaixo de 20, 30 graus negativos e por causa disso os animais morriam de frio. Então a gente fazia tenda do próprio cabelo das cabras. O meu pai comprava a lã, a gente em casa lavava, arrumava, passava ela num pente pra poder abrir e depois levava para essa tenda onde meu pai fazia fio. Meu avó fazia o fio com dois funcionários e meu pai tecia as tendas, às vezes de encomenda. Chegava alguma pessoa que tem um curral no mato aonde dava 30, 40 graus negativos, e eles queriam guardar os animais deles para não morrerem de frio e para permitirem o cruzamento entre eles no período do inverno. E quando chegava o verão, praticamente todas as fêmeas já tinha ovelhinhas, tinha cabritinhos, entendeu. Então meu pai fazia aquele cabelo, enrolava a peça e entregava pra os que encomendaram, e eles vinham, traziam algum dinheiro com o qual nós sobrevivíamos. ${ }^{3}$

O deslocamento dos imigrantes da terra de origem até as Américas era feito na maior parte das vezes de navio. Somente dois dos nossos entrevistados vieram de avião, no Panair do Brasil, isto porque chegaram ao país tardiamente, entre 1949 e 1957. Os primeiros aportaram aqui depois de mais ou menos 30 dias de viagem no mar. ${ }^{4}$ Geralmente partia-se de Beirute com direção à Gênova, na Itália. Ao chegar a esta cidade, permanecia-se nela por alguns dias, dormindo em um hotel que a própria companhia fornecia, até que chegasse o outro navio que os levariam ao Brasil. O relato de Dona Amália Arbache Cury nos mostra como ocorreu este processo. Dona Amália veio de Yabroud para Marília, São Paulo, em 1948, só chegando a Juiz de Fora posteriormente, ao atender ao chamado de sua avó materna para que fizesse companhia para ela e pudesse estudar, já que em São Paulo a escola era muito cara e seu pai não estava naquele momento em condições de pagar o colégio. Segundo Dona Amália:

A viagem de navio foi terrível, porque de Beirute até a Itália, a Gênova na Itália, nós viemos num navio cargueiro, porque foi uma das primeiras viagens depois da guerra, então a gente veio num navio cargueiro. Um andar desse navio era destinado a passageiros. Mas era assim, você não tinha o seu lugar pra ficar não, era um compartimento pras mulheres e um compartimento pros homens. Então ficava a mamãe, eu, meus dois irmãos ali naquela parte das mulheres e os homens numa outra parte. Então era um navio pequeno, foi uma viagem terrível, todo mundo passando mal. Isso foi mais ou menos 15 dias, até chegar em Gênova. Aí quando

\footnotetext{
${ }^{3}$ Entrevista realizada na cidade de Juiz de Fora, no dia 5 de março de 2007.

${ }^{4}$ Entrevista com a senhora Maria Hallack, realizada na cidade de Juiz de Fora, no dia 17 de janeiro de 2007.
} 
chegamos em Gênova ficamos num hotel também que a própria companhia arrumou, pra esperar o navio que íamos pegar para o Brasil. Aí ficamos também mais uns dez dias ali. Esse navio já era melhor, apesar de termos vindo na terceira classe. Só não viemos na primeira classe porque a gente não tinha condição. Mas era bom, era um navio bom mesmo, e a gente era criança, a gente circulava mais. E pra criança tudo é diversão. Neste navio ficamos mais uns 15 dias. Levamos nessa viagem ao todo, um mês. ${ }^{5}$

Houve outras pessoas que tiveram mais sorte com o navio em que embarcaram e fizeram uma viagem mais agradável. Neste caso podemos citar a Dona Marie Hallack, também síria, da cidade de Yabroud, que em 1957, logo que se casou com um brasileiro descendente de persas, veio para o Brasil acompanhando o marido, indo direto para Santos Dumont, localidade próxima a Juiz de Fora. Segundo Dona Marie:

A viagem de navio demorou uns 25 a 30 dias. Porque naquela época avião era coisa de luxo, caríssimo e não tinha facilidade para viajar de avião. O navio é uma coisa que você pode carregar mais bagagem com você, é uma viagem tranqüila, pára em vários países. Então nossa viagem levou quase quarenta dias, porque nós paramos em tudo. Na França, Itália, Espanha, Grécia... A gente andava... O navio parava e a gente descia dois, três dias, depois pegava outro navio. A viagem de navio é uma delícia! Porque lá dentro sempre tem uma programação, festas. É uma viagem gostosa! ${ }^{6}$

Ao aportarem no Brasil estes imigrantes se depararam com um novo mundo. Tiveram que aprender uma nova língua e compreender uma nova cultura, com pessoas diferentes das quais eles conviviam anteriormente. O relato do Senhor José Kassis nos indica uma situação engraçada (e que deve ter acontecido a uma grande maioria daqueles que desembarcaram no Brasil e em outros países) de um imigrante recém chegado a nova pátria. O senhor José Miguel Kassis, sírio, da cidade de Yabroud, chegou ao Brasil em 1953, atendendo ao chamado de seu irmão que já se encontrava estabelecido em São Paulo. Ele só conhecia o irmão por foto, já que quando este emigrou, José estava muito novo ainda, e não se lembrava dele. Mas aproveitando que o serviço na Síria estava escasso decidiu encarar a viagem.

Eu vim de navio. Eu quando cheguei, desci lá do navio, estava carimbando o passaporte, aí eu olhei pela janela e vi um cara de chapéu, parecia meu irmão, porque eu conhecia só o retrato dele. Aí desci. Quando eu desci cumprimentei ele e ele falou: eu não sou seu irmão não [risos]. Eu dormi em Santos. Tudo que eu queria era ficar longe do mar, tanto tempo dentro do navio! Aí de noite meu irmão, [riso] meu irmão me levou pra praia. Aí eu falei: eu não quero ficar vendo praia não. Nessa noite aconteceu uma coisa muito interessante! Fomos jantar em um restaurante eu e ele, a hora que eu cheguei pra comer falei: tudo, menos macarrão [riso], porque o navio era italiano, toda hora macarrão [riso]. Pedi um prato, é... spaghetti. Eu não sabia que spaghetti era macarrão [risos], veio uma travessa de

\footnotetext{
${ }^{5}$ CURY, Amália Arbache. Entrevista realizada na cidade de Juiz de Fora, no dia 11 de janeiro de 2007.

${ }^{6}$ HALLACK, Marie. Entrevista realizada na cidade de Juiz de Fora, no dia 10 de janeiro de 2007. p. 5.
} 
macarrão, uma travessa deste tamanho ${ }^{7}$. [risos] Eu fiz voltar. Aí trouxeram batata frita com filé. ${ }^{8}$

A Senhora Mounira Haddad Rahme também nos deixou um relato interessante sobre sua instalação em Juiz de Fora. Dona Mounira, síria, chegou ao Brasil em 1954, acompanhando seu marido. Foi direto para Juiz de Fora e começou a trabalhar na loja da família, Casa Chic, que existe até hoje, à rua Marechal Deodoro. Não sabia nada de português e foi trabalhando na loja que aprendeu. Mas no início aconteceram situações engraçadas, que demonstram as dificuldades iniciais da adaptação, principalmente no que se refere ao aprendizado da língua, essencial para estabelecer o processo de comunicação com os locais. Segundo Dona Mounira:

\begin{abstract}
No dia seguinte eu desci pra trabalhar aqui na loja, na "Casa Chic". Não falava nada em português, até que aconteceu uma vez um fato. Eu sempre andava com a minha cunhada, a mãe da Leila e a mulher do Wady, aí me perguntavam se a moça conversava e eu não entendia uma palavra, ficava só escutando e não falava nada. Aí virou uma pra outra e falou: Coitadinha, tão bonita e surda e muda. [risos] Aí a minha cunhada falou na hora: Nem surda e nem muda, ela não fala porque ela não entendi nada. ${ }^{9}$
\end{abstract}

Para deixar sua terra natal, enfrentar 30 dias no mar e rumar para o desconhecido, há de ter coragem e motivos. Pudemos, através das entrevistas, levantar cinco pontos que influenciaram na emigração. O primeiro deles está intrinsecamente ligado à questão dos problemas sociais, como as poucas oportunidades de trabalhos, os conflitos constantes, a não existência de terras para todos, os estudos caros, dentre outros. Seguido a este temos as guerras, que fizeram com que muitos fugissem por medo de serem mortos, de serem chamados ao exército (como era o caso do exército turco-otamano, que mal esperava os rapazes crescerem e os colocavam na linha de combate e acabavam sendo os primeiros a morrer) ${ }^{10}$ e mesmo devido à fome surgida com o fim da Primeira Guerra Mundial. O depoimento do Senhor Luiz Abrahão Sefair, descendente de libaneses e nascido em Juiz de Fora, nos ajuda a entender esta situação. O Senhor Luiz é descendente de libaneses e seus pais vieram para o Brasil fugidos dos problemas trazidos pela Primeira Guerra Mundial, mais ou menos em 1920. Segundo o senhor Luiz, seus pais:

\footnotetext{
Vieram por conta da guerra, a guerra provocou miséria e fome, não é. E então, foi a época onde o número de imigrantes aumentou, no mundo todo, mas aqui no Brasil principalmente. E a mamãe veio com todos os irmãos dela, mas o meu pai foi o único da família dele que veio. Ele veio no casco de um navio, quando ele era

${ }^{7}$ Indica com os gestos o tamanho da travessa de macarrão.

${ }^{8}$ Entrevista com o senhor José Miguel Kassis, realizada na cidade de Juiz de Fora, no dia 16 de janeiro de 2007.

${ }^{9}$ Entrevista realizada na cidade de Juiz de Fora, no dia 5 de março de 2007.

${ }^{10}$ Idem.
} 
rapazinho, 16 anos, então ele veio clandestinamente e lamentavelmente nunca pôde voltar não. ${ }^{11}$

Em terceiro lugar, estão as perseguições políticas implementadas pelo poder executivo sírio ou libanês contra aqueles que fizessem oposição a sua forma de governo. Havia também, e esse é um caso específico das mulheres, a vinda ocasionada por casamentos. Muitos imigrantes que vieram para Juiz de Fora, depois de algum tempo tendo acumulado pecúlio, voltaram à terra natal para visitar os parentes, mas também para casar. Contraíam matrimônio, e quando retornavam, suas esposas os acompanhavam deixando seus familiares para trás. Algumas delas foram as únicas da família que vieram morar no Brasil, ficando os pais e irmãos na mesma cidade de nascimento. Este foi o caso de Dona Maria Hallack,, síria, da cidade de Yabroud:

A família do meu marido foi para a Síria para passear, para visitar a mãe, uma senhora idosa. Foi a família toda, e lá encontrei com esse senhor. [riso] Casei com ele e vim embora para o Brasil. Fiquei sete anos no Brasil, depois voltei para minha terra. Fiquei um ano e meio, passeei, aproveitei e tudo, voltei de novo. Fiquei aqui uns anos depois voltei de novo para lá. Vinha e voltava. Cinco, seis vezes. Da minha família não veio mais ninguém para o Brasil. Até hoje não tem ninguém da minha família aqui, só eu. ${ }^{12}$

Por fim, como mais um dos motivos que levaram estes povos a deixarem seu país de origem, encontramos o efeito corrente. Os irmãos, primos, pais, tios, que já estavam estabelecidos em Juiz de Fora, enviavam dinheiro pra a vinda de outros parentes, e diante das notícias de enriquecimento possíveis nas Américas, não se pensava muito para aproveitar esta oferta. Esse efeito colaborou muito para engrossar o caldo imigratório. ${ }^{13} \mathrm{O}$ relato do senhor Georges Sabbagh nos ajuda a compreender melhor este processo. Ao falar de sua irmã que emigrou primeiro junto ao seu marido, ele destaca que ela “(...) chamou o irmão mais velho que veio pra cá. O segundo irmão dela chamou o terceiro, o terceiro chamou o quarto, o quarto chamou o quinto, o quinto chamou o sexto, depois veio o sétimo." ${ }^{14}$ Esse movimento foi realizado principalmente para unir famílias que estavam separadas pela distância marítima existente entre elas e para a ajuda no trabalho (na loja ou na mascateação) que em sua maioria era feito entre pessoas do mesmo sangue.

Estes imigrantes que instalaram-se em território juizfornano, nem sempre vinham diretamente para esta cidade. Os que vieram para Juiz de Fora diretamente, desembarcavam no porto do Rio de Janeiro, e os que dirigiam-se para São Paulo, chegavam à cidade portuária

\footnotetext{
${ }^{11}$ Entrevista com o senhor Luiz Abrahão Sefair, realizada na cidade de Juiz de Fora, no dia 5 de março de 2007.

${ }^{12}$ Entrevista com a senhora Maria Hallack, realizada na cidade de Juiz de Fora, no dia 17 de janeiro de 2007.

${ }^{13}$ Todos estes dados foram retirados da análise que fizemos dos 12 depoimentos que recolhemos.

${ }^{14}$ Entrevista com o senhor Georges Sabbagh, realizada na cidade de Juiz de Fora, no dia 12 de janeiro de 2007.
} 
de Santos. ${ }^{15}$ Mas era mais comum passarem primeiramente pelo estado do Rio de Janeiro (Resende, Cantagalo, Petrópolis), por São Paulo, Paraná, Minas Gerais (Ouro Preto, Raul Soares, Santos Dumont), dentre outros. Wilson de Lima Bastos em seu livro sobre os sírios em Juiz de Fora, destacou que dos seus 66 entrevistados, somente 31 vieram direto para esta cidade, enquanto 37 passaram por outras localidades antes de chegar a território juizforano. (BASTOS, 1988, p. 25) Isto acontecia devido ao fato de estes estrangeiros encontrarem nestas regiões parentes que lhes ajudavam no começo de sua nova vida, até chegar o momento em que decidia-se partir para outras oportunidades e outras localidades e também por serem estas regiões lugares em crescimento onde teriam chance de ganhar dinheiro. Como exemplo disto temos o pai da Senhora Rachel Kassis, descendente de sírios, nascida em Chácara. Seu pai veio para o Brasil em 1919 fugindo dos problemas trazidos pela Primeira Guerra Mundial. Quando chegou ao país passou por vários lugares procurando uma localidade onde pudesse conseguir um bom trabalho. Segundo Dona Rachel, seu pai:

\begin{abstract}
Morou no Paraná primeiro (onde tinha muita serraria), depois não sei como é que ele veio para esses lados, morou aqui em Chapéu D’Uvas. Aí casou aqui mesmo em Chapéu D’Uvas, ficou viúvo, tornou a casar. Aí morou aqui desses lados uns tempos, ele mudou muito! Até Três Ilhas ele morou. Morou Três Ilhas, Santos Dumont, São João Del Rey, Paula Lima, depois foi para Vassouras, no Estado do Rio. Morou em Vassouras. Aí em Vassouras ficou. ${ }^{16}$
\end{abstract}

A escolha da cidade de Juiz de Fora por estes imigrantes, mostrou-se ser devido ao fato de ser esta um lugar de clima bom, bem localizada para o comércio e que oferecia bons trabalhos, no entanto muitas vezes era o acaso que decidia a instalação nesta. Como é o caso do senhor José Kassis, que nos relatou “(...) Até para Juiz de Fora, eu não tinha a intenção. Eu vim visitar uma sobrinha minha e acabei gostando da cidade. (...)” (KASSIS, 2007, p. 4). Aqueles que vieram diretamente para Juiz de Fora, foram devido ao fato de já possuírem algum parente ou conhecido aqui que lhes indicaram o caminho.

Podemos apontar a parte baixa desta cidade como local de excelência da instalação destes imigrantes, seja para morar ou apenas para abrirem suas lojas. A rua Marechal Deodoro foi a mais freqüentada, não só pelos sírios e libaneses, mas também por outros estrangeiros, como os portugueses, italianos, judeus e espanhóis. ${ }^{17}$ As ruas Floriano Peixoto e Barbosa Lima e a Praça da Estação também foram escolhidas pelos sírios e libaneses e suas famílias. A

\footnotetext{
${ }^{15}$ Todos estes dados foram retirados da análise que fizemos dos 12 depoimentos que recolhemos.

${ }^{16}$ Entrevista com a senhora Rachel Kassis, realizada na cidade de Juiz de Fora, no dia 16 de janeiro de 2007.

${ }^{17}$ Entrevista com a senhora Marie Hallack, realizada na cidade de Juiz de Fora, no dia 10 de janeiro de 2007.
} 
historiografia local ainda destaca a presença deste grupo nas ruas Halfeld e XV de Novembro (atual Getúlio Vargas). (ALMEIDA, 2000, p. 200) Esta região foi escolhida estrategicamente por ser o centro nevrálgico do comércio da cidade e pela proximidade com a estação ferroviária, que lhes possibilitava vender aos passageiros que não podiam ir muito longe, porque geralmente o trem voltava dentro de duas horas para as regiões de onde vieram. (ALMEIDA, 2000, p. 201)

O depoimento do senhor Wilson Coury Jabour nos permite observar como era o estilo das moradias na rua Marechal Deodoro, que tinham dois andares, no qual o térreo era reservado para o comércio. Este relato também nos leva a perceber a convivência entre diversas nacionalidades nesta rua, onde a atividade comercial predominava. Também é perceptível que o comércio era a profissão por excelência deste grupo em Juiz de Fora. A mascateação foi a atividade mais exercida pelos integrantes deste grupo nesta cidade, assim como foi para o Brasil como um todo. O senhor Wilson é descendente de libaneses, e nasceu em Juiz de Fora. Seu pai veio da cidade de Beit Edine para o Brasil em 1924 e casou-se em Juiz de Fora com uma descendente de libaneses. Segundo Senhor Wilson seu pai estava construindo:

Um prédio na parte baixa na rua Marechal Deodoro, onde ele construiu a loja no térreo e no andar superior a casa de moradia, onde nós moramos durante muitos anos. Eu saí de lá para casar, em 1956. O papai ficou até a morte. (...) A minha infância foi muito boa, foi na parte baixa da rua Marechal Deodoro. (...) Era um grupo grande de pessoas da mesma faixa etária, é... muitos descendentes de italianos, muitos... muitos descendentes de libaneses, de sírios e até de portugueses. Porque já na década de 40, final de 40 e início de 50 , começaram a vir os portugueses que arrumaram comércio lá embaixo na Marechal Deodoro, com bar e restaurante, e muitos deles se juntaram à nossa turma, e a gente naquele tempo já rapaz, a gente jogava bola junto, ia para os campos aí da várzea, jogar futebol, ia para os bailes junto, para o carnaval junto. Foi uma convivência muito boa. Até hoje a gente se encontra... São muito poucos, a maioria já morreu. ${ }^{18}$

O processo de adaptação à Juiz de Fora perpassa três âmbitos distintos: a gastronomia, os filhos, e os casamentos. Segundo Boris Fausto: “(...) a comida étnica representou, sobretudo nos primeiros tempos da imigração, uma ponte para a terra de origem, à manutenção de um paladar, assim como uma afirmação da identidade". "Um dos significados importantes da comida étnica é o de ser a materialidade de um elo afetivo poderoso para as gerações de imigrantes" (FAUSTO, 1998, p. 56; 58).

Fausto aponta que a comida étnica seria uma forma de manutenção do paladar e de manter uma ligação com a terra natal. Analisando as entrevistas, percebemos que houve uma

\footnotetext{
${ }^{18}$ Entrevista com o senhor Wilson Coury Jabour, realizada na cidade de Juiz de Fora, no dia 3 de outubro de 2006.
} 
mescla da comida brasileira (principalmente arroz e feijão) com a árabe. No entanto prevaleceu a ultima em detrimento da primeira. Como destaca Emma Jabour (descendente de libaneses):

(...) era mais comida árabe que brasileira, no tempo da mamãe era. Assim o quibe era sagrado, uma vez no meio da semana e domingo. Todo domingo tinha quibe, era uma coisa muito engraçada. Não tinha domingo sem quibe. E o charutinho de folha de uva, de repolho, o homus... (...) Fazia lentilha à moda deles lá do Líbano mesmo, aquela lentilha com azeite. Mas um dia da semana era sagrado, tinha feijão preto, com um arrozinho com uma couve, e a gente acostumava não é. Tanto que eu quando eu me casei, era muito engraçado, a minha filha sempre fala isso com os meninos: vocês lembram gente, lá em casa como é que era? A mamãe só fazia feijão preto na segunda feira, o resto da semana ela só fazia comida árabe. E eu também, eu não sabia quase fazer comida brasileira, eu via lá em casa, eu fazia folha de uva quando tinha, fazia charuto de repolho, abobrinha cheia, quibe, lentilha, o tabule e na segunda-feira eu fazia o feijão preto pra eles. Depois não, depois eu deixei, hoje durante a semana eu quase não faço mais, meu filho todo dia come feijão, todo dia. ${ }^{19}$

O relato de Dona Emma nos mostra que a comida árabe era a preferida, mas o tempo trouxe a distância do processo imigratório e as lembranças foram sendo modificadas, e aos poucos a gastronomia brasileira foi abrindo mais espaço no que antes prevalecia o cardápio da terra de origem, e também foi fazendo com que os juizforanos gostassem dos pratos típicos deste grupo. Manter a comida tradicional era uma forma de conservar sua identidade frente a um local com tradições díspares das suas. Mas também, a comida feita no lar era uma forma de mostrar a adaptação ao meio. O depoimento do Senhor Luiz Abrahão Sefair também nos mostra essa presença da comida árabe, mas em conjunto com os pratos brasileiros, já que estavam em um país diferente e com pessoas que não eram originários de sua terra de origem. O Senhor Luiz é descendente de libaneses e seus pais vieram para o Brasil fugidos dos problemas trazidos pela Primeira Guerra Mundial, mais ou menos em 1920. Segundo o senhor Luiz, sua mãe fazia:

A salada tradicional, o tabule, mamãe fazia muita berinjela recheada, abóbora recheada, chuchu recheado, charutinho de repolho, charutinho de folha de uva, fazia quibe assado de bandeja não é, e o quibe frito, buchada (que é um arroz com grão de bico, dentro de uma trouxinha de bucho, ela costurava e era uma delícia!). Ela fazia quibe de abóbora, fazia pastel de verdura com acelga, que era também um sucesso danado... Isso aí ela inseria no cardápio do dia, um prato era hoje, variava. Sempre tinha o feijão, o arroz, a couve, a farofa, essas coisas não é, franguinho. Porque é complicado você fazer a comida típica do país de origem quando os outros não são originários de lá não é? $E$ de repente tem uma visita e às vezes a visita não conhece a comida árabe, então... mas sempre tinha, nunca faltava um quibezinho, o charutinho de repolho. ${ }^{20}$

\footnotetext{
${ }^{19}$ Entrevista com a senhora Emma Jabour, realizada na cidade de Juiz de Fora, no dia 22 de janeiro de 2007.

${ }^{20}$ Entrevista com o senhor Luiz Abrahão Sefair, realizada na cidade de Juiz de Fora, no dia 5 de março de 2007.
} 
Através do uso da memória de nossos entrevistados nos foi possível compreender o processo de inserção dos imigrantes sírios e libaneses na cidade de Juiz de Fora, desde o momento da chegada destes, até a instalação de fato, conhecendo os motivos destes deixarem a terra natal, quando e como chegaram a Juiz de Fora, onde moravam nesta cidade, em que trabalhavam, qual gastronomia era mais favorita, dentre outros pontos importantes. Este artigo nos mostra que fazer um trabalho utilizando-se da História Oral e consequentemente da memória é tão enriquecedor quanto aquele que apenas se utilizam de fontes primárias manuscritas, pois assim temos um contato mais direto com a opinião daqueles que viveram realmente todo o processo imigratório, suas dificuldades, suas esperanças. 


\section{Referências}

\section{Obras secundárias}

ALBERTI, Verena. Ouvir Contar: textos em História Oral. Rio de Janeiro: Editora Fundação Getúlio Vargas, 2004, p. 15.

ALMEIDA, Ludmilla Savry. Sírios e libaneses: redes familiares e negócios. In: Solidariedades e conflitos: história de vida e trajetória de grupos em Juiz de Fora. Juiz de Fora: Editora da UFJF, 2000.

BASTOS, Wilson de Lima. Os sírios em Juiz de Fora. Juiz de Fora: Edições Paraibuna, 1988.

CHRISTO, Maraliz de Castro Vieira. “Europa dos pobres”: a Belle Époque Mineira. Juiz de Fora: EDUFJF, 1994.

ESTEVES, Albino. Álbum do Município de Juiz de Fora. Bello Horizonte: Imprensa Official do Estado de Minas, 1915. Alocado no centro de Memória Murilo Mendes - Juiz de Fora.

FAUSTO, Boris. Imigração: cortes e continuidades. In: NOVAIS, Fernando (coord.) \& SCHWARCZ, Lilia Moritz, (org.). História da Vida Privada no Brasil. São Paulo: Companhia das Letras, 1998, vol. 04.

LOZANO, Jorge Eduardo Alves. Prática e estilos de pesquisa na história oral contemporânea. In: FERREIRA, Marieta de Moraes; AMADO, Janaína (coordenadoras). Usos \& abusos da História Oral. $5^{\text {a }}$ ed. Rio de Janeiro: Editora FGV, 2002, p. 17.

MIRANDA, Sônia Regina. Cidade, Capital e Poder: políticas públicas e questão urbana na velha Manchester Mineira, 1990. 322 p. Dissertação de Mestrado, do curso de Pós-graduação em História da Universidade Federal Fluminense. Rio de Janeiro: Niterói, novembro de 1990.

MONTEIRO, Norma de Góes. Imigração e colonização em Minas (1889-1930). Belo Horizonte: Editora Itatiaia Limitada, 1994.

O PHAROL, 5/2/1901, página 1, coluna 4. Centro de Memória Murilo Mendes, Juiz de ForaMG.

OLIVEIRA, Mônica Ribeiro de. Imigração e industrialização: os alemães e os italianos em Juiz de Fora (1854-1920). Dissertação de Mestrado pela Universidade Federal Fluminense. Niterói: UFF, 1991.

OLIVEIRA, Paulino de. História de Juiz de Fora. $2^{\text {a }}$ ed. Juiz de Fora: Gráfica Comércio e Indústria, 1966. 
PEQUENO, Isabel. Destino árabe tecido por instinto mascate. Imigrantes 150 Anos: Edição Comemorativa dos 150 Anos de Juiz de Fora. Juiz de Fora: Tribuna de Minas, 31 de maio de 2000, p. 30.

SCHWARCZ, Lilia Moritz, (org.). História da Vida Privada no Brasil. São Paulo: Companhia das Letras, 1998, vol. 4

\section{Entrevistas}

CURY, Amália Arbache. Entrevista realizada na cidade de Juiz de Fora, no dia 11 de janeiro de 2007.

HALLACK, Maria. Entrevista realizada na cidade de Juiz de Fora, no dia 17 de janeiro de 2007.

HALLACK, Marie. Entrevista realizada na cidade de Juiz de Fora, no dia 10 de janeiro de 2007. p. 05.

JABOUR, Emma. Entrevista realizada na cidade de Juiz de Fora, no dia 22 de janeiro de 2007.

JABOUR, Wilson Coury. Entrevista realizada na cidade de Juiz de Fora, no dia 03 de outubro de 2006.

KASSIS, José Miguel. Entrevista realizada na cidade de Juiz de Fora, no dia 16 de janeiro de 2007.

KASSIS, Rachel. Entrevista realizada na cidade de Juiz de Fora, no dia 16 de janeiro de 2007.

RAHME, Mounira Haddad. Entrevista realizada na cidade de Juiz de Fora, no dia 05 de março de 2007.

SABBAGH, Georges. Entrevista realizada na cidade de Juiz de Fora, no dia 12 de janeiro de 2007.

SABBAGH, Sônia. Entrevista realizada na cidade de Juiz de Fora, no dia 12 de janeiro de 2007.

SEFAIR, Luiz Abrahão. Entrevista realizada na cidade de Juiz de Fora, no dia 05de março de 2007. 